\title{
Solution Structure of the Endonuclease Domain from the Master Replication Initiator Protein of the Nanovirus Faba Bean Necrotic Yellows Virus and Comparison with the corresponding Geminivirus and Circovirus Structurest,‡
}

\author{
Susana Vega-Rocha ${ }^{1}$, Bruno Gronenborn ${ }^{2}$, Angela M. Gronenborn ${ }^{3}$, and Ramón Campos- \\ Olivas ${ }^{1, *}$ \\ 1 Structural and Computational Biology Program. Spanish National Cancer Center (CNIO). Madrid 28029. \\ Spain \\ 2 Institut des Sciences du Vegetal. Centre National de la Recherche Scientifique. 91198 Gif-sur-Yvette Cedex, \\ France \\ 3 Department of Structural Biology. University of Pittsburgh School of Medicine, BST3, 3501 5th Avenue, \\ Pittsburgh, PA 15261. USA
}

\begin{abstract}
Nanoviruses are a family of plant viruses that posses a genome of multiple circular single-stranded DNA (ssDNA) components and are strikingly similar in their replication mode to the plant geminiviruses and to the circoviruses that infect birds or mammals. These viruses multiply by rolling circle replication using virus-encoded multifunctional replication initiator proteins (Rep proteins) that catalyze the initiation of replication on a double-stranded DNA (dsDNA) intermediate and the resolution of the ssDNA into circles. Here we report the solution NMR three-dimensional structure of the endonuclease domain from the Master Rep (M-Rep) protein of faba bean necrotic yellows virus (FBNYV), a representative of the nanoviruses. The domain comprises amino acids 2-95 (MRep$_{2-95}$ ) and its global fold is similar to those previously described for the gemini- and circovirus Rep endonuclease domain, consisting of a central 5 -stranded antiparallel $\beta$-sheet covered on one side by an $\alpha$-helix and irregular loops and on the other, more open side of the domain, by an $\alpha$-helix containing the catalytic tyrosine residue (the catalytic helix). Longer domain constructs extending to amino acids 117 and 124, were also characterized. They contain an additional $\alpha$-helix, are monomeric and exhibit catalytic activity indistinguishable from that of M-Rep2-95. The binding site for the catalytic metal was identified by paramagnetic broadening and maps to residues on the exposed face of the central $\beta$-sheet. A comparison with the previously determined Rep endonuclease domain structures of tomato yellow leaf curl Sardinia virus (TYLCSV), a geminivirus, and that of porcine circovirus type 2 (PCV2) Rep allows the identification of a positively charged surface that
\end{abstract}

\footnotetext{
${ }^{\dagger}$ This work was supported in part by Plan Nacional de Biotecnologia grant BIO2001-2287 from the Spanish Ministry of Science and Technology (to R.C.O) and the Intramural AIDS Targeted Antiviral Program of the Office of the Director of the National Institute of Health (to A.M.G.).

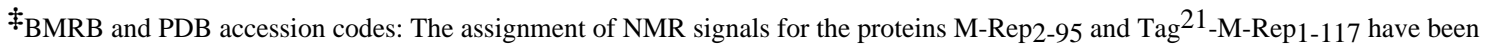
deposited at the BMRB with access numbers 7112 and 7218, respectively. The 30-conformer ensemble, as well as the average minimized structure, have been deposited in the PDB with access code 2HWT.

Corresponding author: Ramón Campos-Olivas, Structural and Computational Biology Program., Spanish National Cancer Center (CNIO)., C. Melchor Fernandez Almagro, 3, Madrid 28029. Spain, Tel: +34-912246900, Fax: +34-912246976, E-mail: rcampos@cnio.es.
} 
is most likely involved dsDNA binding, and reveals common features shared by all endonuclease domains of nanovirus, geminivirus, and circovirus Rep proteins.

Nanoviruses possess the smallest known virions and the smallest individual genome components of all plant viruses (1) and are causative disease agents for a variety of important food and fodder legumes (2). The nanovirus genome is multipartite and consists of 6 to 8 molecules of circular ssDNA, ranging in size from 977 to 1111 nucleotides, individually encapsidated in small icosahedral virions of 17-20 nm in diameter. Each component encodes, in virion (+) sense polarity, a single protein and contains a common region that is part of the viral origin of replication (3). This region is partially conserved among all genomic components of a given nanovirus and contains sequence elements (including a common nonanucleotide sequence flanked by inverted repeats that may form a hairpin-loop structure) functionally equivalent to those found in the intergenic regions of plant geminiviruses and animal circoviruses $(4,5)$, that possess only one or two genomic components. The replication of the multiple nanovirus genomic DNAs is initiated by a single replication initiator protein, the socalled master Rep protein (M-Rep) (6), that cleaves a specific phosphodiester bond in the conserved nonanucleotide sequence at the viral replication origin. Despite the occurrence of multiple additional Rep proteins encoded by other DNA molecules associated with the nanoviruses, solely the M-Rep is required and sufficient to catalyze replication initiation of the nanovirus genomic DNAs $(3,7,8)$. M-Rep is a multifunctional protein of $\sim 33 \mathrm{kDa}$ involved in both initiation and termination of rolling circle replication. It is related in sequence and biological function to the rolling circle replication initiator proteins of gemini- and circoviruses.

The distinct biochemical activities of Rep proteins from gemini-, circo- and nanoviruses are associated with different parts of the protein: (1) Sequence specific recognition of the replication origin and endonuclease activity, i.e. DNA cleavage and joining at the replication origin, reside in the N-terminal region (9-13). (2) Oligomerization of geminivirus Rep has been assigned to the central region, comprising amino acids 119-180 (12), although a corresponding domain has not yet been identified for nanovirus or circovirus Rep proteins. (3) The ATPase activity, essential for virus replication (14), resides in the C-terminal part of Rep from around amino acid 180 onwards (15), and very recently, helicase activity of Rep or its ATPase domain oligomers have been demonstrated for two different geminivirus Rep proteins $(16,17)$.

Amino acids involved in the different activities of the replication initiator proteins constitute characteristic motifs conserved throughout large families of genetic entities that multiply by rolling circle replication, including gemini-, circo- and nanoviruses $(18,19)$. In particular, three conserved sequence motifs of rolling circle replication initiator proteins (19) are localized in the N-terminal endonuclease domain of Rep. The recently determined structures of the endonuclease domains of the Rep proteins from the geminivirus tomato yellow leaf curl Sardinia virus (TYLCSV) (13) and from porcine circovirus type 2 (PCV2) (20) revealed structural and biochemical features corroborating the functional roles of these sequence motives (see below) and further rationalized their conservation in the RCR initiator proteins. Since nanovirus replication initiator proteins, including the M-Rep, are smaller than those of gemini- and circoviruses, and since their amino acid motifs are slightly different, it is instructive to determine and compare the structure of the endonuclease domain of a nanovirus M-Rep protein with those of the corresponding gemini- and circoviruses. Interestingly, infectivity of cloned viral DNAs has only been achieved for a single nanovirus to date, namely faba bean necrotic yellows virus (FBNYV), an expanding pathogen of legume crops, rendering it especially important and amenable to reverse genetics (21). Origin-specific DNA cleavage and nucleotidyl transfer activities have been demonstrated in vitro for the complete FBNYV MRep protein, with tyrosine 79 identified as the catalytic residue (3). In addition, divalent 
$\mathrm{Mg}^{2+}$ or $\mathrm{Mn}^{2+}$ cations were found to be essential for DNA cleavage by two different nanovirus M-Rep proteins $(3,22)$.

Here we report the three-dimensional solution NMR structure of the catalytic domain of the M-Rep protein of FBNYV and further characterize its in vitro endonuclease activity. In addition, we investigated the metal dependence of the DNA cleavage reaction, and identified residues involved in metal binding. Finally, a comparative analysis of the present structure with those of previously determined representative Rep endonuclease domains of a geminivirus (13) and a circovirus (20) is presented.

\section{EXPERIMENTAL PROCEDURES}

\section{Protein Expression and Purification}

A putative FBNYV Master Rep (GenBank accession Y11405) endonuclease domain comprising amino acids 1-95 was cloned by PCR introducing Ndel (5') and BamHI (3') restriction sites into twoplasmids, pET3a and pET15b. The protein overexpressed from $\mathrm{pET} 15 \mathrm{~b}$ contains a 20 amino acid polyhistidine-containing tag $\left(\mathrm{Tag}^{20}\right.$ ) at its $\mathrm{N}$-terminus (i.e. $\mathrm{Tag}^{20}-\mathrm{M}$ $\mathrm{Rep}_{1-95}$ ). Two further constructs were designed, containing extensions of the putative domain past the catalytic tyrosine residue, comprising one or two potential $\alpha$-helices. These consisted of residues 1-117 and 1-124 (M-Rep ${ }_{1-117}$ and M-Rep ${ }_{1-124}$ ), respectively, and were cloned into a pET28a vector (Novagen) which contains a prescission protease cleavage site after the polyhistidine sequence, resulting in a polypeptide with an extra $\mathrm{N}$-terminal tag of 22 residues $\left(\mathrm{Tag}^{22}\right)$. Another variant of the pET3a M-Rep ${ }_{1-95}$ construct that included an extra methionine preceding Met1 was also constructed by site-directed mutagenesis using the QuikChange SiteDirected Mutagenesis kit (Stratagene).

All proteins were expressed in E.coli strain Rosetta BL21 (DE3) plysS (Novagen). Uniformly ${ }^{15} \mathrm{~N}$ and/or ${ }^{13} \mathrm{C}$-labeled proteins were prepared by growth in minimal media containing ${ }^{15} \mathrm{NH}_{4} \mathrm{Cl}$ and/or ${ }^{13} \mathrm{C}$-glucose as the sole nitrogen and carbon sources, respectively. Cell mass was produced in rich medium, followed by exchange of cells into a small volume (typically 1/3) of labeled medium at high cell density (23). Cells were induced with $0.5 \mathrm{mM}$ IPTG after one hour, allowing for growth recovery and unlabeled metabolite clearance, and grown overnight at $18{ }^{\circ} \mathrm{C}$. For the M-Rep ${ }_{1-95}$ constructs the protein from the soluble fraction was purified in three steps: two ion exchange chromatography steps (GE Healthcare) using a Q-sepharose column (which excludes the protein) and a SP-sepharose column (which retains the protein), followed by size exclusion chromatography on Superdex 75 (GE Healthcare). The load and wash buffer for the $\mathrm{Q}$ column was $20 \mathrm{mM}$ sodium phosphate (pH 6.6), $0.3 \mathrm{M} \mathrm{NaCl}$ and $1 \mathrm{mM} \mathrm{DTT}$, and $\mathrm{NaCl}$ was reduced to $0.1 \mathrm{M} \mathrm{NaCl}$ for the SP column. For elution, the same buffer but with $1 \mathrm{M} \mathrm{NaCl}$ was used in both ion exchange columns. For the polypeptides Tag $^{19}-\mathrm{M}-\mathrm{Rep}_{1-95}, \mathrm{Tag}^{21}{ }^{2} \mathrm{M}-\mathrm{Rep}_{1-117}$ and $\mathrm{Tag}^{21}{ }^{-\mathrm{M}-\mathrm{Rep}_{1-124}}$ (see results) purification was achieved in a two step protocol: (1) affinity chromatography on Talon resin (Invitrogen) using immobilized cobalt, and (2) gel filtration on Superdex 75. Samples for NMR analysis contained 0.6-0.8 mM M-Rep2-95 protein (see results) in $20 \mathrm{mM}$ sodium phosphate buffer (pH 6.6), 0.6 $\mathrm{M} \mathrm{NaCl}, 0.01 \% \mathrm{NaN}_{3}$ and $1 \mathrm{mM}$ DTT. In the case of $\mathrm{Tag}^{21}-\mathrm{M}-\mathrm{Rep}_{1-117}$ and Tag ${ }^{21}-\mathrm{M}$ -

$\mathrm{Rep}_{1-124}$ the highest concentration obtainable was $0.4 \mathrm{mM}$. Proteolytic cleavage with prescission protease $\left(1 \mathrm{~h} \mathrm{at} 4{ }^{\circ} \mathrm{C}\right)$ was carried out on Tag ${ }^{21}$-containing ${ }^{15} \mathrm{~N}$-labelled proteins, and cleavage products were examined by $2 \mathrm{D}^{1} \mathrm{H}_{-}{ }^{15} \mathrm{~N}$ NMR, without separation, in order to identify resonances belonging to the tags. This enabled us to directly analyze the spectra of the Rep extension constructs, which were recorded using the non-cleaved, $\mathrm{Tag}^{21}$-containing proteins, because cleavage of the affinity tags resulted in a significantly lower solubility, insufficient for the 3D NMR experiments necessary to assign their NMR resonances. 


\section{Endonuclease Activity Assays}

Cleavage assays were carried out with each purified domain (M-Rep $1-95$, M-Rep $2-95$, Tag 21 . M-Rep ${ }_{1-117}$, and Tag ${ }^{21}-\mathrm{M}-\mathrm{Rep}_{1-124}$, see results) using a 12mer ssDNA oligonucleotide containing the conserved nonamer sequence on the viral strand of FBNYV (F12 $=5^{\prime}$ -

TAGTATT^ACCCC- $3^{\prime}$, where ${ }^{\wedge}$ denotes the cleavage site and the nonamer sequence is underlined). Reactions included $20 \mu \mathrm{M}$ protein in $20 \mathrm{mM}$ Tris $\mathrm{pH} 7.4,0.1 \mathrm{M} \mathrm{NaCl}$, in the absence or presence of $20 \mu \mathrm{M}$ of the oligonucleotide F12, in a final volume of $10 \mu \mathrm{l}$. Samples were incubated at $37^{\circ} \mathrm{C}$ for 5 minutes, followed by the addition of 2x SDS-PAGE sample buffer and heating for 5 minutes at $95-100^{\circ} \mathrm{C}$ before loading onto the gel. Covalent Rep-DNA adducts were separated by SDS-PAGE (12\% polyacrylamide) and stained with Coomassie for visualization. The effects of divalent metal ions on the cleavage by the different constructs were followed by including $2.5 \mathrm{mM}$ of $\mathrm{MgCl}_{2}, \mathrm{MnCl}_{2}, \mathrm{ZnCl}_{2}$ or $\mathrm{CaCl}_{2}$ in the respective reaction buffer prepared without any metals. Each series contained one sample in which the divalent metal was prevented from interacting with protein and/or DNA by adding $30 \mathrm{mM}$ EDTA before addition of the ssDNA substrate.

\section{NMR Spectroscopy}

All NMR experiments were carried out at $293 \mathrm{~K}\left(20^{\circ} \mathrm{C}\right)$ on Bruker Avance 600 (with a cryogenic probe) and $700 \mathrm{MHz}$ spectrometers. ${ }^{1} \mathrm{H},{ }^{15} \mathrm{H}$ and ${ }^{13} \mathrm{C}$ backbone and side chain resonances of M-Rep 2-95 and $\mathrm{Tag}^{21}{ }^{2} \mathrm{M}-\mathrm{Rep}_{1-117}$ were assigned by three-dimensional (3D) double- and triple-resonance NMR experiments, as reported (24). Interproton distance constraints for M-Rep $2-95$ were derived from $3 \mathrm{D}$ and four-dimensional $(4 \mathrm{D}){ }^{15} \mathrm{~N}$ - and ${ }^{13} \mathrm{C}$ separated nuclear Overhauser enhancement (NOE) experiments. Torsion angle restraints were derived from backbone chemical shifts using the program TALOS (25). Heteronuclear ${ }^{3} \mathrm{~J}$ couplings were measured by quantitative J-correlation Spectroscopy (26). Heteronuclear ${ }^{15} \mathrm{~N}$ $\left\{{ }^{1} \mathrm{H}\right\}$ NOE experiments were acquired at $700 \mathrm{MHz}$ in an interleaved fashion using an interscan delay of $6 \mathrm{~s}$, and echo-antiecho gradient selection for pure phase signals in the indirect dimension and water suppression. The ${ }^{15} \mathrm{~N}\left\{{ }^{1} \mathrm{H}\right\}$ NOE value for each amide was determined as the intensity ratio of the correlation in the ${ }^{1} \mathrm{H}$-saturated experiment and that in the reference, non-saturated experiment. Errors bars for the ${ }^{15} \mathrm{~N}\left\{{ }^{1} \mathrm{H}\right\}$ NOEs were determined from the baseline noise of the two spectra.

\section{Structure Calculation}

Structures were calculated from the experimental constraints in torsion angle space using CYANA 2.1. (27). Upper-limit distance constraints of 2.7, 3.3, 5.0 and 5.5 $\AA$ (with $0.5 \AA$ added for NOEs involving methyl protons) were used, corresponding to strong-, medium-, weak- and very weak-intensity NOE cross-peaks, respectively. Additional NOEs were automatically assigned (in the $3 \mathrm{D}^{15} \mathrm{~N}$-separated NOESY and 2D NOESY recorded in $\mathrm{D}_{2} \mathrm{O}$ ) using the algorithm NOAH (28). All methyl resonances of Val and Leu residues were stereospecifically assigned using a sample produced with $10 \%{ }^{13} \mathrm{C}$-glucose (29). Structural statistics were calculated with CYANA (30), MOLMOL (31), and PROCHECK (32), and figures were generated with MOLMOL and Swiss-PdbViewer 3.7 (33). Structural superpositions were carried out with Superpose (34).

\section{Mapping of Divalent Metal Binding Site by NMR}

The analysis of divalent metal binding was performed by comparing the perturbed (with added divalent metal) and the non-perturbed (reference) $2 \mathrm{D}^{1} \mathrm{H}_{-}{ }^{15} \mathrm{~N}$ HSQC spectra acquired under identical conditions. Titrations were performed at $700 \mathrm{MHz}$ in the following manner: the protein was dialyzed into $50 \mathrm{mM}$ Tris, $0.6 \mathrm{M} \mathrm{NaCl}, 1 \mathrm{mM} \mathrm{DTT}, \mathrm{pH} 7.0$ at a final concentration of $100 \mu \mathrm{M}$ and a sample volume of $350 \mu \mathrm{l}$, and variable amounts of $\mathrm{MnCl}_{2}(1: 0,1: 0.4,1: 0.8$ and 1:1.6 protein:metal molar ratio) were added. Unpaired electrons are a particularly efficient 
source of relaxation, even when present at low concentration, resulting in a general broadening of resonances. Therefore, the number of scans was increased for successive additions (216, 216,240 , and 304) of the paramagnetic ion to compensate for signal loss due to broadening. Only well resolved and isolated peaks were used for metal binding analysis. Peak intensities were measured with NMR View (35) and normalized with respect to the number of scans and to the intensities of the corresponding signals in the reference spectrum. Amide correlations considered affected by divalent metal binding were those that exhibited a significant decrease in intensity for the three additions (1:0.4, 1:0.8 and 1:1.6) compared to the average decrease noted for all amides. In this manner, residues whose resonances broadened beyond the cut-off value defined by the average signal decrease minus one standard deviation were considered as strongly affected in a specific fashion: for the 1:0.4 titration point, this meant a reduction in signal size below $73 \%$, for $1: 0.8$ below $55 \%$ and for $1: 1.6$ below $25 \%$. Weakly but specifically affected residues were those whose intensities were below the cut-off only in the last two additions, 1:0.8 and 1:1.6. The rest of the residues are considered as non-affected by metal binding to the protein domain.

\section{RESULTS AND DISCUSSION \\ Protein Production and Characterisation}

The FBNYV M-Rep full length protein was expressed as a histidine-tagged polypeptide and, upon purification, exhibited significant aggregation resulting in high molecular weight complexes (data not shown). Therefore, we focused on accurately delineating the boundaries of the stably folded $\mathrm{N}$-terminal endonuclease domain. After inconclusive results were obtained from limited proteolysis experiments performed using the full length protein, we designed three different protein truncations: the putative catalytic domain of M-Rep, comprising residues 1-95 (M-Rep $1-95$, with or without an N-terminal tag), a larger construct including one additional stretch, predicted to be $\alpha$-helical, as well as an even larger protein that contained two of the $\alpha$-helices predicted to form the potentialoligomeriz ation domain of Rep. Purity, labeling and identity of the expressed Rep domains were assessed by mass spectrometry (M-Rep 1-95, $_{\text {, }}$ $\mathrm{Tag}^{20}{ }_{-\mathrm{M}-\mathrm{Rep}_{1-95}}$ Tag $^{22}{ }_{-\mathrm{M}-\mathrm{Rep}_{1-117}}$, and Tag ${ }^{22}-\mathrm{M}-\mathrm{Rep}_{1-124}$ expected mass are $10956 \mathrm{Da}$., 13119 Da., $15997 \mathrm{Da}$. and $16871 \mathrm{Da}$., respectively). The observed masses were $10823 \mathrm{Da}$., $12987 \mathrm{Da} ., 15868 \mathrm{Da}$. and $16741 \mathrm{Da}$., respectively $(\Delta=-133,-132,-129,-130)$. Therefore, the non-tagged polypeptide comprises residues 2-95 (M-Rep2-95), after in vivo processing of the $\mathrm{N}$-terminal methionine 1 (36). In the case of the tagged proteins, Met1 at the $\mathrm{N}$-terminus of the tag was also not present, resulting in the polypeptides $\mathrm{Tag}^{19}{ }^{1} \mathrm{M}-\mathrm{Rep}_{1-95}, \mathrm{Tag}^{21}{ }^{2} \mathrm{M}-$ Rep $_{1-117}$, andTag ${ }^{21}$-M-Rep $1-124$.

In order to evaluate the possible role of methionine in position 1 on the stability of the domain and its DNA interaction, we also produced a plasmid coding for a M-Rep ${ }_{1-95}$ mutant containing an extra methionine residue before the ATG start codon of the native sequence, since the analogous residue in the biochemically and structurally related relaxases TrwC and Tral from conjugative plasmids (see discussion below) was shown to be critical for ssDNA binding $(37,38)$. The resulting protein was expected to contain an extra Met residue preceding the native Met1 residue in M-Rep. Mass spectroscopic analysis of the purified protein revealed a molecular mass of $10956 \mathrm{Da}$., corresponding precisely to the polypeptide M-Rep $\mathrm{p}_{1-95}$. Therefore, in vivo processing led to the desired $\mathrm{N}$-terminal sequence containing methionine at position 1.

Protein yields for all constructs were very similar (5-10 mg/l culture), decreasing when produced isotopically labeled for NMR (3-6 mg/l culture). The longer polypeptides, MRep $_{1-117}$ and M-Rep $1-124$, with or without the Tag ${ }^{21}$ tag, exhibited solubility problems at concentrations above $0.4 \mathrm{mM}$, while the protein M-Rep $2-95$ could be concentrated up to $\sim 0.8$ $\mathrm{mM}$ and therefore was selected for structure determination. M-Rep ${ }_{1-95}$ became only available 
after the structure of M-Rep2-95 had been determined. All overexpressed proteins were monomeric in solution, as judged by gel filtration chromatography and analytical ultracentrifugation (data not shown). Therefore, the addition of 22 or 29 amino acids at the Ctermini of the longer proteins, $\mathrm{Tag}^{21}-\mathrm{M}-\mathrm{Rep}_{1-117}$ and Tag ${ }^{21}-\mathrm{M}-\mathrm{Rep}_{1-124}$, are not sufficient for ordered oligomerization, although it can not be excluded that these regions, in the context of the complete Rep protein, are part of the oligomerization domain. The reduced solubility exhibited by these longer constructs as compared to their shorter counterpart may indeed indicate a tendency for multimerization by these $\mathrm{C}$-terminal extensions.

\section{Endonuclease Activity Assays}

The intergenic region of all the DNA components of FBNYV contains the conserved nonanucleotide sequence that is an essential part of the origin for initiation of RCR. For the full length protein, the catalytic endonuclease activity has been described (3). In order to evaluate whether the FBNYV M-Rep domains investigated here were bona fide endonuclease domains possesig origin DNA cleavage activity, we used a 12 nucleotide fragment in the enzymatic assay (F12, see Experimental Procedures), that included the nonamer with the cleavage site. As shown in Figure 1A, domains M-Rep ${ }_{2-95}$, M-Rep ${ }_{1-95}$, Tag ${ }^{21}-\mathrm{M}-\mathrm{Rep}_{1-117}$, and $\mathrm{Tag}^{21}$-M-Rep ${ }_{1-124}$ were catalytically active, cutting the F12 oligonucleotide at the $\mathrm{T}^{\wedge} \mathrm{A}$ phosphodiester bond, and remaining bound to the $5^{\prime}$ end of the 5 nucleotides (ACCCC, Figure 1A) of the substrate oligonucleotide. This results in a slower migration on SDS-PAGE of the protein-DNA adduct than that of the free protein (Figure 1A). Cleavage efficiency was ca. 50 $\%$ for all three polypeptides, thus 50\% of the protein was converted to the DNA-bound species. Since the shorter M-Rep2-95 construct was sufficient for catalytic activity, all subsequent structural work was carried out with this protein.

\section{Divalent Metal Effect on Endonuclease Activity}

A requirement for $\mathrm{Mg}^{2+}$ or $\mathrm{Mn}^{2+}$ for efficient DNA cleavage had been reported for full length Rep of the geminivirus TYLCSV (39) and for M-Rep of the nanovirus FBNYV (3). We therefore tested several different divalent metals using M-Rep2-95 (Figure 1B). No cleavage occurred with $\mathrm{CaCl}_{2}$, while $\mathrm{MgCl}_{2}$ and $\mathrm{ZnCl}_{2}$ allowed the reaction to occur, but only about $5 \%$ of the protein was converted to the adduct. Most effective was $\mathrm{MnCl}_{2}$, either alone or simultaneously with $\mathrm{MgCl}_{2}$, resulting in conversion of about $50 \%$ of the free domain into the covalent adduct. EDTA addition, as expected, completely abrogated cleavage. This established that for M-Rep2-95 divalent metals are needed and that the order of efficiency was: $\mathrm{Mn}^{2+}$ > $\mathrm{Mg}^{2+}=\mathrm{Zn}^{2+}$, while no cleavage was detected with $\mathrm{Ca}^{2+}$.

\section{NMR Spectroscopy and Structure Determination}

The structural integrity of the three proteins was assessed by 2D 1H- 15N HSQC Spectroscopy. The spectrum for M-Rep2-95 is shown in Figure 2, and a comparison with those of the longer $\mathrm{Tag}^{21}$-M-Rep 1 -117, and Tag ${ }^{21}$-M-Rep1-124 proteins is provided in Supplementary Figure S1 (Supporting Information). All three spectra display excellent dispersion and the number of observed signals corresponds approximately to the expected number in each case. Virtually complete assignments of ${ }^{1} \mathrm{H},{ }^{13} \mathrm{C}$, and ${ }^{15} \mathrm{~N}$ resonances using standard $3 \mathrm{D}$ and $4 \mathrm{D}$ triple resonance experiments on $\mathrm{U}_{-}{ }^{15} \mathrm{~N}$, and $\mathrm{U}_{-}{ }^{13} \mathrm{C},{ }^{15} \mathrm{~N}$ labeled samples have been reported for $\mathrm{M}$ $\mathrm{Rep}_{2-95}$ and $\mathrm{Tag}^{21}{ }_{-\mathrm{M}-\mathrm{Rep}_{1-117}}$ (24) and deposited (BMRB accession numbers 7112 and 7218, respectively). For M-Rep2-95 all expected backbone amide proton resonances are observed in the spectrum, with the exception of those of R3, C7, E47, R69, M81, and K82. The NHع1 resonance of the W8 indol group (Figure 2) appears broad and exhibits an unusual shift (HN,N: $8.7,113 \mathrm{ppm}$ ), most likely caused by an interaction with the side chain of K68, producing a cation- $\pi$ interaction, as observed in the structure of the folded domain (see below). Several Arg side chain HNe resonances were also observed (Figure 2). For the Tag $^{21}-\mathrm{M}-\mathrm{Rep}_{1-117}$, and 
$\mathrm{Tag}^{21}$-M-Rep $1-124$ proteins (Figure S1), the signals were less dispersed and significantly overlapped in the central region of the spectrum, caused by the presence of the unstructured affinity tags, as well as disordered parts of the extensions. This is reflected in the backbone assignments for these proteins (24). Given the overall superior spectral quality and solubility of the shortest construct M-Rep2-95, this protein was selected for a complete structure determination.

Structure calculations were carried out using a large number of interproton distance constrains obtained from analysis of 2D NOESY, 3D ${ }^{15} \mathrm{~N}$-edited NOESY, 4D ${ }^{13} \mathrm{C}$-edited, ${ }^{15} \mathrm{~N}$-edited NOESY, and $4 \mathrm{D}^{13} \mathrm{C}$-edited, ${ }^{13} \mathrm{C}$-edited NOESY spectra, supplemented by $(\varphi, \phi)$ dihedral angle constraints obtained from TALOS analysis of chemical shifts (and consistent ${ }^{3} \mathrm{~J}_{\mathrm{HNH} \alpha}$ values from 3D HNHA), and $\chi 1$ dihedral angle constraints (Table 1). All X-Pro peptide bonds were found to be trans based on the observation of $\alpha-\delta / \delta^{\prime}$ sequential NOEs, with the exception of Pro90 that adopts a cis conformation, as revealed by the presence of $\alpha-\alpha$ sequential NOEs. The two cysteine residues, Cys 7 and Cys 9 , are reduced, as revealed by their characteristic ${ }^{13} \mathrm{C}_{\beta}$ chemical shifts of 30.3 and $29.7 \mathrm{ppm}$, respectively. $\beta$-strands as well as their arrangement within the $\beta$-sheet were identified by analysis of the inter-strand backbone NOEs and confirmed by $\mathrm{H}-\mathrm{D}$ exchange analysis of amide backbone resonances after dissolving the sample in $\mathrm{D}_{2} \mathrm{O}$ (Figure S2). The final ensemble of 30 conformers is well defined (Figure 3A) and agrees well with all the NMR-derived geometrical constraints. No interproton distance or torsion angle violations $>0.39 \AA$ and $>8.2^{\circ}$, respectively, were observed. The percentage of residues in the most favourable region of the Ramachandran map is $75.5 \%$ and only $1.3 \%$ of residues are found in disallowed regions. All pertinent structural statistics are provided in Table 1. A significant improvement of the structure quality is obtained ( $82 \%$ in most favorable regions and none in disallowed regions) when the disordered regions, 35-38 and 69-84, are omitted. This part of the structure contains the only residue (S80) found in a disallowed region of the $(\varphi, \phi)$ map and one of the two (A37 but not K50) in the generously allowed region. The 30conformer ensemble, as well as the average minimized structure, have been deposited in the PDB under access code 2HWT.

The boundaries of the folded domain of M-Rep2-95 were derived using the following criteria: flexible regions associated with low heteronuclear ${ }^{15} \mathrm{~N}\left\{{ }^{1} \mathrm{H}\right\}$ NOEs (Figure 4) and devoid of long-range ${ }^{1} \mathrm{H}-{ }^{1} \mathrm{H}$ NOEs were considered to be outside the domain. In addition, relatively narrow resonance lines were present for the flexible $\mathrm{N}$ - and $\mathrm{C}$-termini. However, the experimental ${ }^{15} \mathrm{~N}\left\{{ }^{1} \mathrm{H}\right\}$ NOE values were significantly affected by saturation transfer (40), as several amides exceeded the maximum theoretical value of 0.84 at $70 \mathrm{MHz}{ }^{15} \mathrm{~N}$ frequency (Figure 4). Nevertheless, qualitative conclusions with respect to flexibility are not affected by this experimental artifact. Backbone amides with significant flexibility are represented in orange in the ribbon representation in Figure 3B. At the N-terminus Q4 and V5 $\left({ }^{15} \mathrm{~N}\left\{{ }^{1} \mathrm{H}\right\} \mathrm{NOE}\right.$ $<0.6)$ are flexible, but I6 is clearly ordered $\left({ }^{15} \mathrm{~N}\left\{{ }^{1} \mathrm{H}\right\} \mathrm{NOE}>0.7\right)$. Within the protein, two other relatively flexible regions $\left({ }^{15} \mathrm{~N}\left\{{ }^{1} \mathrm{H}\right\}\right.$ NOE values of $\left.0.5-0.6\right)$ are noted. The first comprises residues 35-40 and connects strands $\beta_{2}$ and $\beta_{3}$. The second region followshelix $\alpha_{2}$, including residues 71-75. At the C-terminus, the E95 reveals increased flexibility $\left({ }^{15} \mathrm{~N}\left\{{ }^{1} \mathrm{H}\right\}\right.$ NOE of 0.55), although some tertiary interproton NOEs have been observed between E95 and L21, K26, and Y27. Taken these data together allows us to conclude that for M-Rep2-95 the well folded domain contains residues 6-94.

\section{Three Dimensional Structure Description}

The overall fold of M-Rep2-95 is shown as a ribbon diagram in Figure 3B. It consist of five $\beta$-strands and two $\alpha$-helices, arranged in a central 5-stranded anti-parallel $\beta$-sheet ( $\beta_{1}$ (residues 8-13), $\beta_{2}$ (27-34), $\beta_{3}$ (40-47), $\beta_{4}$ (65-67) and $\beta_{5}$ (91-94); Figure $S 2$ ), decorated on its periphery by two $\alpha$-helices, each one on a different side of the $\beta$-sheet. Helix $\alpha_{1}$ (54-58), the loops 
connecting $\alpha_{1}$ to the strands in the central $\beta$-sheet (loop $\beta_{3}-\alpha_{1}$ and loop $\alpha_{1}-\beta_{4}$ ), and a long loop connecting strands $\beta_{1}$ and $\beta_{2}$ cover one face of the sheet. The other side of the $\beta$-sheet is much more exposed, only partially covered by helix $\alpha_{2}$ (76-79), preceded and followed by two 310 helical turns (73-75 and 83-85), and its flanking loops. Although the overall structure is quite well defined, the precision is lower in regions with a lower number of geometric restrains and these regions coincide with those for which increased motion was deduced from relaxation data. For example, the variability in structure observed for the region connecting the $\beta_{4}$ strand to the $\alpha_{2}$ helix and the latter to the $\beta_{5}$ strand (Figure 3A) correlates with the low ${ }^{15} \mathrm{~N}\left\{{ }^{1} \mathrm{H}\right\} \mathrm{NOE}$ values for amide resonances of residues 71-75 (in orange) and with the absence of backbone amide resonances for residues 68,81 , and 82 (in magenta), most likely resulting from exchange with $\mathrm{H}_{2} \mathrm{O}$ and/or conformational exchange. Indeed, one could envisage a "breathing" motion between the $\alpha_{2}$ helix and the $\beta$-sheet that may cause such conformational exchange. Removal of this region, residues 35-38 (loop $\beta_{2}-\beta_{3}$ ) and 69-84 (loop $\beta_{4}-\beta_{5}$, including $\alpha_{2}$ ), as well as the flexible terminal tails from the calculation of coordinate precision, results in a significant improvement (Table 1). In fact, within the 30 conformer ensemble, the helix $\alpha_{2}$ and the two flanking $3_{10}$ helical turns are not populated consistently to $100 \%$, but only $57 \%, 50 \%$, and $43 \%$ of the conformers adopt the 76-79 helix, and the 73-75 and 83-85 turns, respectively.

Analysis of the chemical shifts for the extension constructs Tag ${ }^{21}-\mathrm{M}-\mathrm{Rep}_{1-117}$, and Tag ${ }^{21}-\mathrm{M}-$ $\mathrm{Rep}_{1-124}$, in conjunction with angular information derived from ${ }^{3} \mathrm{~J}_{\mathrm{HNH} \alpha}$ values, allowed to qualitatively assess whether additional secondary structure elements or structured regions are present in these larger proteins when compared to $\mathrm{M}-\mathrm{Rep}_{2-95}$, for which the 3D structure was determined. TALOS (25) analysis of both longer proteins revealed that strand $\beta_{5}$ is extended from residue 95 to residue 98 and the presence of an additional helical turn, $\alpha_{3}$, involving residues 103-106. No significant differences in chemical shifts were noted between $\mathrm{Tag}^{21}-\mathrm{M}$ $\mathrm{Rep}_{1-124}$ and $\mathrm{Tag}^{21}{ }^{-\mathrm{M}-\mathrm{Rep}_{1-117}}$. Apart from the C-terminal residues of M-Rep $2-95$ that are followed by the extensions 96-117 and 96-124 in the longer constructs, the largest variation in chemical shifts (illustrated in the ${ }^{1} \mathrm{H}_{-}{ }^{15} \mathrm{~N}$ HSQC spectra in Figure S1) between M-Rep2-95 and $\mathrm{Tag}^{21}-\mathrm{M}-\mathrm{Rep}_{1-117}$ (or Tag ${ }^{21}-\mathrm{M}-\mathrm{Rep}_{1-124}$ ) are consistently observed in three areas of the protein (illustrated in Supplementary Figure S3): (1) the N-terminal tail, including the first residue of strand $\beta_{1}$ (residues 2-8); (2) the last half of strand $\beta_{3}$ and the loop $\beta_{3}-\alpha_{1}$ connecting it to helix $\alpha_{1}$ (residues 43-46 and 48-53, respectively); and (3) the loop $\beta_{4}-\alpha_{2}$ and the catalytic helix $\alpha_{2}$ (residues 70-80). These areas are located in the lower left region in the structure as displayed in the left hand side of Figure 3B, suggesting that elongation of strand $\beta_{5}$ directs the polypeptide chain to run over the central $\beta$-sheet. In addition, helical turn $\alpha_{3}(103-106)$ likely packs against the left part of the exposed face (left hand side of Figure 3B) through its conserved leucine residue, possibly contacting the catalytic helix $\alpha_{2}$ and the loops $\beta_{3^{-}} \alpha_{1}$ and $\beta_{4^{-}} \alpha_{2}$ and thereby displacing the $\mathrm{N}$-terminal flexible tail. This potential packing of the helical turn $\alpha_{3}$ against the folded domain is transmitted to relatively remote sites, that also experience a significant variation in chemical shifts between the short and the longer constructs (see residues 63, 82, and 85 in Figure S3). This additional element not present in the structure determined here could influence the flexibility in the loop $\beta_{4}-\alpha_{2}$ right before the catalytic helix $\alpha_{2}$ However, any such altered flexibility had little effect on the cleavage efficiency (Figure 1A). On the other hand, the $\alpha_{3}$ helical turn contains two basic amino acids conserved in the M-Rep of all members of the genus Nanovirus but not in those of BBTV. Together with other basic residues in that surface area of the protein these residues could potentially participate in dsDNA binding, thereby influencing activity (see below).

\section{Delineation of the $\mathrm{Mn}^{2+}$ Binding Site}

Since it was known that $\mathrm{Mg}^{2+}$ or $\mathrm{Mn}^{2+}$ ions were necessary for DNA cleavage by the intact TYLCSV geminivirus Rep (39) and for M-Rep of the nanovirus FBNYV (3) we delineated the binding site for $\mathrm{Mn}^{2+}$ in the structure of the endonuclease domain of FBNYV M-Rep2-95. 
Titration of the protein with increasing amounts of $\mathrm{MnCl}_{2}(1: 0,1: 0.4,1: 0.8$, and 1:1.6 protein:Mn, molar ratio) by $2 \mathrm{D}^{1} \mathrm{H}_{-}{ }^{15} \mathrm{~N}$ HSQC spectroscopy readily revealed those resonances that specifically broadened (Figure 5) prior to an overall resonance broadening that made detection difficult. The latter occurs since paramagnetic ions also cause general broadening (due to intermolecular electron-spin relaxation) of all resonances, in addition to the specific line broadening experienced by amide resonances close to the metal binding site. Examples of strongly and weakly specifically affected amides as defined in Experimental Procedures are resonances 84 and 41, respectively, while resonances 14, 32, and 42 are not affected (Figure 5). Intensity changes for all backbone and side chain amide resonances upon manganese addition are provided in Supplementary Figure S4. Care was taken to normalize the intensity changes with respect to the number of scans and to the signal intensity in the absence of metal to unambiguously identify specific broadening effects beyond the general drop in intensity of 1:0.82:0.59:0.32 observed along the titration series for all the amide resonances (see Experimental Procedures). No chemical shift changes were noted, indicating $\mathrm{Mn}^{2+}$ binding is weak. Titration with $\mathrm{Mg}^{2+}$ ions was also carried out and again, no chemical shift changes were identified.

In the structure, the strongly and weakly specifically affected $\mathrm{NH}$ and $\mathrm{NH}_{2}$ atoms are shown as red $\left(\mathrm{E} 36, \mathrm{~N} 39_{\delta}, \mathrm{Q} 43_{\varepsilon}\right.$ and D84) and orange $\left(\mathrm{N} 13_{\delta}, \mathrm{Q} 34, \mathrm{Q} 34_{\varepsilon}, \mathrm{I} 40\right.$ and H41) spheres, respectively, with greek letters indicating the position of side chain $\mathrm{NH}_{2}$ groups (Figure 6). Amide sites that do not comply with the stringent cut-off criteria but show indications of some specific broadening are 9, 11, 13, 33, 35, 37, 39, 66, 67, 83, and 85 (Supplementary Figure S4) and are shown in grey in Figure 6. The parts of the structure affected by metal binding reside on the exposed side of the $\beta$-sheet close to the $\beta_{2}-\beta_{3}$ - loop and the $3_{10}$ helical turn following the catalytic helix $\alpha_{2}$. Given the fact that manganese is generally coordinated by six ligands in a regular octahedral arrangement, preferring oxygen atoms in ligands rather than nitrogen and sulphur (41), it is reasonable to propose that the side chains of residues E33, H41, and D84 coordinate the $\mathrm{Mn}^{2+}$ ion, given their spatial proximity (as well as the conservation in nanovirus Rep proteins, see below and Figure 7). Additional ligands could be $\mathrm{H}_{2} \mathrm{O}$ molecules (41), or the affected residues E36 and Q43, although the former amino acid would cause a significant conformational change, and the latter is, due to its chemical nature $\left(\mathrm{Mn}^{2+}\right.$ coordination is usually mediated by Asp, Glu, and His sidechains), a rare ligand for manganese. Nevertheless, given the established role of the two conserved histidines in divalent metal coordination for endonuclease domains belonging to the $\mathrm{HUH}$ family $(37,42,43)$ and the dramatic broadening caused by $\mathrm{Mn}^{2+}$ in the sidechain resonances of Q43 from the FBNYV domain (Figure S4), the role of the glutamine residue conserved in nanovirus (and circovirus) Rep domains in metal binding (possibly in an alternative mode with respect the HUH-containing domains) can not be excluded. Studies with point mutants of the Rep domains may aid in determining the precise role of the conserved glutamine residue in divalent metal ion coordination. This, however, requires a quantitative metal binding assay which currently is lacking.

\section{Comparison of the FBNYV Master Rep Endonuclease Domain with those from Gemini- and Circoviruses}

The present structure is the prototype for a nanovirus Master Rep protein, given the high level of sequence similarity between FBNYV and a large number of nanovirus Rep endonuclease domains, including that from BBTV, a virus from another genus in the Nanoviridae family (Figure 7).. In contrast, the M-Rep endonuclease domain of FBNYV exhibits low sequence identity to the Rep sequence of the geminivirus TYLCSV (12\%), while that of the circovirus PCV2 occupies an intermediate position with $30 \%$ sequence identity. Structurally, however, all endonuclease domains of these Rep proteins are similar, with conservation of the secondary structure elements $\beta_{1}, \beta_{2}, \beta_{3}, \beta_{4}, \beta_{5}$, and $\alpha_{2}$ (FBNYV nomenclature, Figure 7). A major difference is the absence of both the $\alpha_{1}$ helix (red) and the $\beta_{1}-\beta_{5}$ mini $\beta$-sheet extension (purple) 
in FBNYV Rep, compared to the TYLCSV and PCV2 Rep domains, while helices $\alpha_{1}$ in FBNYV and $\alpha_{.2}$ in PCV2 (green) are substituted by the $\beta_{6}-\beta_{7}$ hairpin in TYLCSV Rep (Figure $8 \mathrm{~A}$ ). The nanovirus Rep endonuclease domain is the least decorated structure and remains the core structure for all viral Rep endonuclease domains known to date, including that of the Rep from the dependovirus AAV5 (42), which possesses a linear ssDNA genome. This basic fold is also common to the HUH motif-containing relaxase proteins from conjugative plasmids, but they appear circularly permuted with respect to the viral Rep domain structures (43), resulting in much lower DALIZ-scores (44) between relaxases and Rep domains $(Z=0.7-1.8)$, in relation to the comparison among relaxases $(\mathrm{Z}=28.0)$ or among the viral Reps $(\mathrm{Z}=3.8-7.9$;

Supplementary Table S1). A quantitative evaluation of the structural similarity in the central 5 -stranded $\beta$-sheet between the four different viral Rep domains and the two relaxases is provided in Supplementary Table S2, revealing a highly similar arrangement of strands $\beta_{1}$ to $\beta_{5}$ (FBNYV nomenclature), with rmsd values of backbone heavy atom coordinates below $\sim 2.0$ $\AA$ for all pairwise comparisons. Inclusion of the catalytically essential tyrosine and lysine residues (except for the relaxase TrwC, in which this residue is not present) in the structural comparison consistently increases the rmsd values (see below). This indicates that the positioning of these two residues at $i$ and $i+3$ positions (at $i+4$ for AAV5 Rep and Tral) with respect to the conserved $\beta$-sheet introduces a real and potentially important variation in the different structures. In fact, a striking structural difference between the circovirus Rep endonuclease domain on the one hand and those of the gemini- and nanovirus Rep counterparts on the other, is the orientation of the catalytic helix relative to the central $\beta$-sheet (Figure 8A): in the circovirus endonuclease domain this helix runs almost parallel to the $\beta$-strands, whereas in the gemini- and nanovirus domains the catalytic helix axis is oriented at angles of $\sim 45$ and $\sim 70$ degrees relative to the central $\beta$-strand, respectively. This may be related to the different positioning of dsDNA recognition elements (iteron sequences (45)) relative to the conserved nonamer sequence, the target of the endonucleolytic action. On the other hand, the currently available Rep endonuclease domains representing four virus families (and the relaxases) are structurally equally distant from each other with no transparent evolutionary relationship.

As can be seen from the comparison of structures (Figures 7 and 8B-D), residues in the conserved motifs I, II and III (46) are generally located in structurally equivalent positions, although their side chain conformation differs between the three structures. Motif I residues are located on the $\beta_{1}$ strand (CFTL in FBNYV) with two of the residues pointing towards the exposed surface of the $\beta$-sheet (C9 and T11) and the other two (F10 and L12) towards the hydrophobic core of the domain. As suggested previously for TYLCSV (13), the hydrophobic residues in motif I contribute to the domain architecture and stability while the two exposed residues ( $\mathrm{F} / \mathrm{C} / \mathrm{V}$ and $\mathrm{T}$ for the gemini-, nano- and circovirus Rep, respectively) can participate in the recognition of the nucleic acid. The first, variable position, may allow for some degree of specificity towards parts of the viral DNA other than the conserved nonanucleotide sequence.

Motif II (HUQ for nano and circovirus, HUH for geminivirus, where U denotes a large, hydrophobic amino acid) is located on the central $\beta_{3}$ strand, with the two conserved residues residing on the exposed face of the central $\beta$-sheet, and residue $U$ buried in the hydrophobic core. The two conserved histidine residues were proposed to be involved in divalent metal coordination (19), a concept that was supported by the structure of the endonuclease domain of the dependovirus AAV5 Rep (42), that contained a $\mathrm{Zn}^{2+}$ ion coordinated by structurally homologous residues to the two histidines and a glutamic acid (H57, H59, and E49 in TYLCSV, Figure 8B). Alternatively, results presented here for the structure of the nanovirus domain as well as data recently reported for the circovirus domain (20), suggest that the first coordinating histidine could be replaced by an acidic side chain in the Rep proteins of these viruses, reaching down to the exposed surface of the $\beta$-sheet from the loop following the catalytic helix $\beta_{2}$ (shown in yellow). In this way, metal coordination in nanovirus Rep would involve the side chains of residues H41, E33, and D84 in FBNYV (Figure 8C), and H57, E48, and E100 in the circovirus 
PCV2 (Figure 8D). In the model geminivirus structure shown in Figure 8B none of the acidic side chains following the catalytic helix (D107 or D109) points towards the presumed divalent metal site, therefore most likely will not be involved. This is partially supported by the properties of TYLCSV Rep mutant D107A that is unaffected in their endonuclease and nucleotidyl transferase activities (B. Gronenborn and J. Brevet, unpublished results). The general location of the divalent metal site is also consistent with the electrostatic surface potential of the proteins (Figure 8E). Motif III (YXXKE/D) contains the active site tyrosine (Y79 in the nanovirus), catalyzing DNA cleavage and nucleotidyl transfer reactions $(3,47)$, an essential lysine (48) and an acidic residue, the function of which remains undetermined. The catalytic tyrosine is located in all three cases in the so-called catalytic helix (yellow in Figure 8A-D). The Tyr and Lys side chains point in a similar direction towards the exposed side of the $\beta$-sheet, although in the nanovirus structure (Figure $8 \mathrm{C}$ ) the tyrosine is slightly further away from the $\beta$-sheet. The higher mobility observed for this region in the FBNYV Rep domain structure, compared to the corresponding gemini- and circovirus ones, may allow for this residue to reach an equivalent position, even if it is not structurally locked in.

\section{Catalytic Mechanism and Substrate Recognition by Viral RCR Rep Endonuclease Domains}

Based on all the available structural results and inspired by the catalytic mechanism of the biochemically and structurally related bacterial relaxases $(38,49)$ we propose a model for the cleavage reaction performed by the viral Rep proteins. It consists of three steps: (1) binding and precise positioning of the phosphate group at the scissile bond, aided by the divalent metal ion and the positively charged side chain of the conserved lysine (K82 in Figure 8C). Interaction with the lysine will also induce the appropriate polarization of the phosphodiester bond. This is followed by (2) the nucleophilic attack of the hydroxyl group of the catalytic tyrosine residue (Y79 in Figure 8C) on the phosphate with formation of a penta-coordinated phosphate intermediate. In the last step (3) the tyrosine hydroxyl proton is abstracted by a general base, for example the metal coordinating histidine residue (H57, H41, and H57 in TYLCSV, FBNYV, and PCV2 Rep, respectively), and transferred to a nearby base (for example E36 in FBNYV, Figure 8C, or homologous residues in gemini and circovirus Rep, Figure 7). This results in formation of the phosphotyrosine bond and the covalent adduct between the protein and the 3 '-fragment of the substrate ssDNA. The leaving $5^{\prime}$-fragment of the substrate ssDNA is protonated by a properly positioned residue acting as a general acid (for example, H59 in TYLCVS, Figure 8.B, although there is no corresponding residue that could play that role in the nanovirus and circovirus structures) creating the free $3^{\prime}-\mathrm{OH}$. Mutagenesis studies based on the three available Rep domain structures may lead to further insights into the mechanistic details of the endonuclease reaction catalyzed by Rep and provide proof of this structure-based hypothesis.

Prior to the cleavage reaction, Rep proteins have to locate the conserved nonanucleotide in the context of the replication competent viral dsDNA intermediate. As proposed for TYLCSV (13), partially validated for PCV2 by the characterization of a complex with viral dsDNA (20), and clearly established in a AAV5 Rep-dsDNA complex structure (50), a cluster of positively charged residues and positive electrostatic surface potential is responsible for high affinity binding to specific dsDNA sequences, be it the iterons (45) or other sequence elements. This positively charged surface area is present in all three RCR viral Rep endonuclease domains (Figure $8 \mathrm{E}$ ) and involves the $\mathrm{N}$-terminal and $\mathrm{C}$-terminal tails of the domains, the mini $\beta$-sheet extensions of the gemini- and circovirus Rep proteins, and the corresponding region of the nanovirus Rep (Figure 8A). Remarkably, the first $\beta$-strand of the mini $\beta$-sheet extension that is present in the TYLCSV geminivirus Rep protein and preceding the motif I sequence $\left(\beta_{1}\right.$, purple in Figure 7) was predicted to constitute an iteron related domain involved in specific recognition of the viral dsDNA (51). For the nanovirus domain the surface electrostatic potential could be even more positive in the context of the complete Rep protein as evidenced 
by the potential packing of the $\alpha_{3}$ helical turn containing two conserved basic amino acids that are present in the proteins extending beyond amino acid 95 (Figure 7; see above). Although direct experimental evidence by EMSA experiments on complex formation is currently only available for the circovirus PCV2, it is reasonable to assume that similar dsDNA recognition and binding exists for all viral RCR Rep proteins. Recognition of dsDNA sequences that confer specificity of a given Rep protein for its cognate genome may also position the conserved nonanucleotide (that is spatially distinct from the bound dsDNA site) such that it contacts the exposed side of the central p-sheet close to the catalytic residues (Figure 8B-D). The electrostatic surface potential in this region is slightly negative (Figure $8 \mathrm{E}$ ); therefore the presence of a bound divalent cation would be essential to allow binding of the highly negatively charged nonanucleotide at the catalytic site. The combination of high affinity binding of nearby dsDNA sequences coupled with a transient and low affinity metal-mediated binding of the single stranded region would result in repulsion of the $5^{\prime}$ part of the nonanucleotide sequence following Repmediated DNA cleavage and aid to displace this sequence from the protein. In this manner, it would be available to serve as a primer for subsequent DNA synthesis.

\section{Supplementary Material}

Refer to Web version on PubMed Central for supplementary material.

\section{Acknowledgements}

D. Padro and FJ. Blanco (CNIO) are acknowledged for technical support and continuous scientific support, respectively. SVR acknowledges a FPI predoctoral fellowship, and RCO is a Ramón y Cajal fellow, both from the Spanish Ministry of Science and Technology.

\section{Abbreviations}

AAV5

adeno-associated virus 5

BBTV

banana bunchy top virus

dsDNA

double-stranded DNA

EMSA

electrophoretic mobility shift assay

FBNYV

faba bean necrotic yellows virus

M-Rep

master Rep

NMR

nuclear magnetic resonance

NOE

nuclear Overhauser effect

PCV2

porcine circovirus type 2

RC 
rolling circle

\section{RCR}

$$
\mathrm{RC} \text { replication }
$$

Rep

replication initiator protein

rmsd

root-mean-squared deviation

SDS-PAGE

polyacrylamide gel electrophoresis in the presence of sodium dodecyl sulphate

ssDNA

single-stranded DNA

TYLCSV

tomato yellow leaf curl Sardinia virus

\section{References}

1. Vetten, HJ.; Chu, PWG.; Dale, JL.; Harding, R.; Hu, J.; Katul, L.; Kojima, M.; Randles, JW.; Sano, Y.; Thomas, JE. Nanoviridae. In: Fauquet, CM.; Mayo, MA.; Maniloff, J.; Desselberger, U.; Ball, LA., editors. Virus Taxonomy, VIII Report of the ICTV. Academic Press; Elsevier, London: 2005. p. 343-52.

2. Katul L, Vetten HJ, Maiss E, Makkouk KM, Leseman DE, Casper R. Characterisation and serology of virus-like particles associated with faba bean necrotic yellows. Ann Appl Biol 1993;123:629-647.

3. Timchenko T, de Kouchkovsky F, Katul L, David C, Vetten HJ, Gronenborn B. A single rep protein initiates replication of multiple genome components of faba bean necrotic yellows virus, a singlestranded DNA virus of plants. J Virol 1999;73:10173-10182. [PubMed: 10559333]

4. Lazarowitz SG, Wu LC, Rogers SG, Elmer JS. Sequence-specific interaction with the viral AL1 protein identifies a geminivirus DNA replication origin. Plant Cell 1992;4:799-809. [PubMed: 1392596]

5. Mankertz A, Persson F, Mankertz J, Blaess G, Buhk HJ. Mapping and characterization of the origin of DNA replication of porcine circovirus. J Virol 1997;71:2562-2566. [PubMed: 9032401]

6. Katul L, Timchenko T, Gronenborn B, Vetten HJ. Ten distinct circular ssDNA components, four of which encode putative replication-associated proteins, are associated with the faba bean necrotic yellows virus genome. J Gen Virol 1998;79:3101-3109. [PubMed: 9880028]

7. Timchenko T, Katul L, Sano Y, de Kouchkovsky F, Vetten HJ, Gronenborn B. The master rep concept in nanovirus replication: identification of missing genome components and potential for natural genetic reassortment. Virology 2000;274:189-195. [PubMed: 10936099]

8. Horser CL, Harding RM, Dale JL. Banana bunchy top nanovirus DNA-1 encodes the 'master' replication initiation protein. J Gen Virol 2001;82:459-464. [PubMed: 11161286]

9. Heyraud-Nitschke F, Schumacher S, Laufs J, Schaefer S, Schell J, Gronenborn B. Determination of the origin cleavage and joining domain of geminivirus Rep proteins. Nucl Acids Res 1995;23:910916. [PubMed: 7731803]

10. Jupin I, Hericourt F, Benz B, Gronenborn B. DNA replication specificity of TYLCV geminivirus is mediated by the amino-terminal 116 amino acids of the Rep protein. FEBS Lett 1995;362:116-120. [PubMed: 7720856]

11. Choi IR, Stenger DC. Strain-specific determinants of beet curly top geminivirus DNA replication. Virology 1995;206:904-912. [PubMed: 7856103]

12. Orozco BM, Kong LJ, Batts LA, Elledge S, Hanley-Bowdoin L. The multifunctional character of a geminivirus replication protein is reflected by its complex oligomerization properties. J Biol Chem 2000;275:6114-6122. [PubMed: 10692401] 
13. Campos-Olivas R, Louis JM, Clerot D, Gronenborn B, Gronenborn AM. The structure of a replication initiator unites diverse aspects of nucleic acid metabolism. Proc Natl Acad Sci USA 2002;99:10310 10315. [PubMed: 12130667]

14. Desbiez C, David C, Mettouchi A, Laufs J, Gronenborn B. Rep protein of tomato yellow leaf curl geminivirus has an ATPase activity required for viral DNA replication. Proc Natl Acad Sci USA 1995;92:5640-5644. [PubMed: 7777563][erratum appears in Proc Natl Acad Sci U S A 1995 Nov $21 ; 92(24): 11322]$

15. Orozco BM, Miller AB, Settlage SB, Hanley-Bowdoin L. Functional domains of a geminivirus replication protein. J Biol Chem 1997;272:9840-9846. [PubMed: 9092519]

16. Clérot D, Bernardi F. DNA helicase activity is associated with the replication initiator protein rep of tomato yellow leaf curl geminivirus. J Virol 2006;80:11322-11330. [PubMed: 16943286]

17. Choudhury NR, Malik PS, Singh DK, Islam MN, Kaliappan K, Mukherjee SK. The oligomeric Rep protein of Mungbean yellow mosaic India virus (MYMIV) is a likely replicative helicase. Nucleic Acids Res 2006;34:6362-6377. [PubMed: 17142233]

18. Gorbalenya AE, Koonin EV, Wolf YI. A new superfamily of putative NTP-binding domains encoded by genomes of small DNA and RNA viruses. FEBS Lett 1990;262:145-148. [PubMed: 2156730]

19. Ilyina TV, Koonin EV. Conserved sequence motifs in the initiator proteins for rolling circle DNA replication encoded by diverse replicons from eubacteria, eucaryotes and archaebacteria. Nucl Acids Res 1992;20:3279-3285. [PubMed: 1630899]

20. Vega-Rocha S, Byeon IL, Gronenborn B, Gronenborn AM, Campos-Olivas R. Solution Structure, Divalent Metal and DNA Binding of the Endonuclease Domain from the Replication Initiation Protein from Porcine Circovirus 2. J Mol Biol 2007;367:473-487. [PubMed: 17275023]

21. Timchenko T, Katul L, Aronson M, Vega-Arreguin JC, Ramirez BC, Vetten HJ, Gronenborn B. Infectivity of nanovirus DNAs: induction of disease by cloned genome components of Faba bean necrotic yellows virus. J Gen Virol 2006;87:1735-1743. [PubMed: 16690940]

22. Hafner GJ, Stafford MR, Wolter LC, Harding RM, Dale JL. Nicking and joining activity of banana bunchy top virus replication protein in vitro. J Gen Virol 1997;78:1795-1799. [PubMed: 9225058]

23. Marley J, Lu M, Bracken C. A method for efficient isotopic labeling of recombinant proteins. J Biomol NMR 2001;20:71-75. [PubMed: 11430757]

24. Vega-Rocha SV, Gronenborn B, Gronenborn AM, Campos-Olivas R. ${ }^{1} \mathrm{H},{ }^{13} \mathrm{C}$, and ${ }^{15} \mathrm{NNMR}$ Assignment of the Master Rep Protein Nuclease Domain from the Nanovirus FBNYV. J Biomol NMR. 200610.1007/s 10858-006-9085-y

25. Cornilescu G, Delaglio F, Bax A. Protein backbone angle restraints from searching a database for chemical shift and sequence homology. J Biomol NMR 1999;13:289-302. [PubMed: 10212987]

26. Bax A, Vuister GW, Grzesiek S, Delaglio F, Wang AC, Tschudin R, Zhu G. Measurement of homoand heteronuclear J couplings from quantitative J correlation. Methods Enzymol 1994;239:79-105. [PubMed: 7830604]

27. Güntert P, Mumenthaler C, Wuthrich K. Torsion angle dynamics for NMR structure calculation with the new program DYANA. J Mol Biol 1997;273:283-298. [PubMed: 9367762]

28. Mumenthaler C, Güntert P, Braun W, Wüthrich K. Automated combined assignment of NOESY spectra and three-dimensional protein structure determination. J Biomol NMR 1997;10:351-362. [PubMed: 9460241]

29. Neri D, Szyperski T, Otting G, Senn H, Wiithrich K. Stereospecific nuclear magnetic resonance assignments of the methyl groups of valine and leucine in the DNA-binding domain of the 434 repressor by biosynthetically directed fractional ${ }^{13} \mathrm{C}$ labeling. Biochemistry 1989;28:7510-7516. [PubMed: 2692701]

30. Herrmann T, Güntert P, Wüthrich K. Protein NMR structure determination with automated NOE assignment using the new software CANDID and the torsion angle dynamics algorithm DYANA. J Mol Biol 2002;319:209-227. [PubMed: 12051947]

31. Koradi R, Billeter M, Wüthrich K. MOLMOL: a program for display and analysis of macromolecular structures. J Mol Graph 1996;14:51-55. 29-32. [PubMed: 8744573]

32. Laskowski RA, Rullmannn JA, Mac Arthur MW, Kaptein R, Thornton JM. AQUA and PROCHECKNMR: programs for checking the quality of protein structures solved by NMR. J Biomol NMR 1996;8:477-486. [PubMed: 9008363] 
33. Kaplan W, Littlejohn TG. Swiss-PDB Viewer (Deep View). Brief Bioinform 2001;2:195-197. [PubMed: 11465736]

34. Maiti R, Van Domselaar GH, Zhang H, Wishart DS. SuperPose: a simple server for sophisticated structural superposition. Nucl Acids Res 2004;32:W590-594. [PubMed: 15215457]

35. Johnson BA. Using NMRView to visualize and analyze the NMR spectra of macromolecules. Methods Mol Biol 2004;278:313-352. [PubMed: 15318002]

36. Hirel PH, Schmitter MJ, Dessen P, Fayat G, Blanquet S. Extent of N-terminal methionine excision from Escherichia coli proteins is governed by the side-chain length of the penultimate amino acid. Proc Natl Acad Sci U S A 1989;86:8247-8251. [PubMed: 2682640]

37. Guasch A, Lucas M, Moncalian G, Cabezas M, Perez-Luque R, Gomis-Ruth FX, de la Cruz F, Coll M. Recognition and processing of the origin of transfer DNA by conjugative relaxase TrwC. Nat Struct Biol 2003;10:1002-1010. [PubMed: 14625590]

38. Larkin C, Datta S, Harley MJ, Anderson BJ, Ebie A, Hargreaves V, Schildbach JF. Inter- and intramolecular determinants of the specificity of single-stranded DNA binding and cleavage by the F factor relaxase. Structure 2005;13:1533-1544. [PubMed: 16216584]

39. Laufs J, Traut W, Heyraud F, Matzeit V, Rogers SG, Schell J, Gronenborn B. In vitro cleavage and joining at the viral origin of replication by the replication initiator protein of tomato yellow leaf curl virus. Proc Natl Acad Sci U S A 1995;92:3879-3883. [PubMed: 7732000]

40. Grzesiek S, Bax A. The importance of not saturating water in protein NMR. Application to sensitivity enhancement and NOE measurements. J Am Chem Soc 1993;115:12593-12594.

41. Glusker JP. Structural aspects of metal liganding to functional groups in proteins. Adv Protein Chem 1991;42:1-76. [PubMed: 1793004]

42. Hickman AB, Ronning DR, Kotin RM, Dyda F. Structural unity among viral origin binding proteins: crystal structure of the nuclease domain of adeno-associated virus Rep. Mol Cell 2002;10:327-337. [PubMed: 12191478]

43. Datta S, Larkin C, Schildbach JF. Structural insights into single-stranded DNA binding and cleavage by F factor TraI. Structure 2003;11:1369-1379. [PubMed: 14604527]

44. Holm L, Park J. DaliLite workbench for protein structure comparison. Bioinformatics 2000;16:566567. [PubMed: 10980157]

45. Argüello-Astorga GR, Guevara-Gonzalez RG, Herrera-Estrella LR, Rivera-Bustamante RF. Gemini virus replication origins have a group-specific organization of iterative elements: a model for replication. Virology 1994;203:90-100. [PubMed: 8093156]

46. Koonin EV, Ilyina TV. Computer-assisted dissection of rolling circle DNA replication. Biosystems 1993;30:241-268. [PubMed: 8374079]

47. Laufs J, Schumacher S, Geisler N, Jupin I, Gronenborn B. Identification of the nicking tyrosine of geminivirus Rep protein. FEBS Letters 1995;377:258-262. [PubMed: 8543063]

48. Hoogstraten RA, Hanson SF, Maxwell DP. Mutational analysis of the putative nicking motif in the replication- associated protein (AC1) of bean golden mosaic geminivirus. Mol Plant Microbe Interact 1996;9:594-599. [PubMed: 8810074]

49. Boer R, Russi S, Guasch A, Lucas M, Blanco AG, Perez-Luque R, Coll M, de la Cruz F. Unveiling the molecular mechanism of a conjugative relaxase: The structure of TrwC complexed with a 27mer DNA comprising the recognition hairpin and the cleavage site. J Mol Biol 2006;358:857-869. [PubMed: 16540117]

50. Hickman AB, Ronning DR, Perez ZN, Kotin RM, Dyda F. The nuclease domain of adeno-associated virus rep coordinates replication initiation using two distinct DNA recognition interfaces. Mol Cell 2004;13:403-414. [PubMed: 14967147]

51. Arguello-Astorga GR, Ruiz-Medrano R. An iteron-related domain is associated to Motif 1 in the replication proteins of geminiviruses: identification of potential interacting amino acid-base pairs by a comparative approach. Archives of Virology 2001;146:1465-1485. [PubMed: 11676411] 


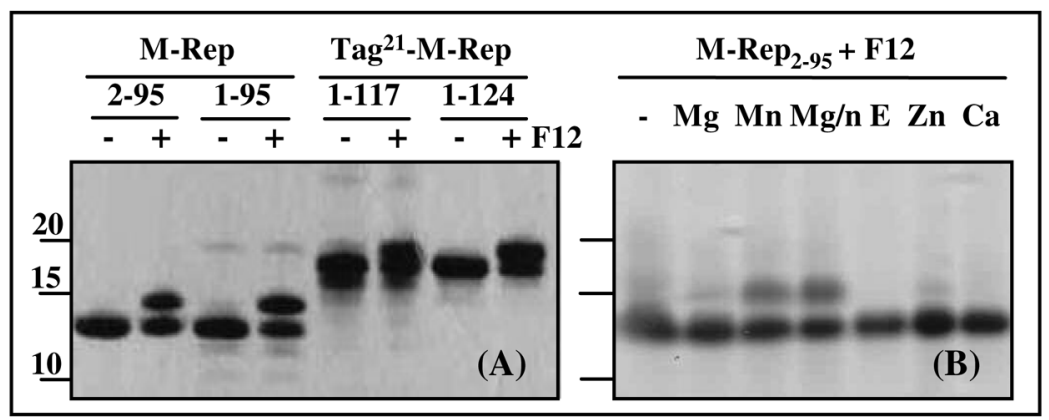

FIGURE 1.

(A) Endonuclease activity of FBNYV M-Rep protein domains. Oligonucleotide F12 (TAGTATT^ACCCC), containing the conserved nonamer sequence of the nanovirus replication origin (in italics) with five nucleotides after the scissile bond $(\wedge)$ was used as substrate. The reaction was monitored by SDS-PAGE (12\%), followed by Coomassie staining. The change in electrophoretic mobility compared to the free proteins $(-)$ after covalent adduct formation between the protein and the penta-nucleotide is easily seen (+). (B) Effect of divalent metals on the cleavage of oligonucleotide F12 by M-Rep $2-95$. Lanes are labelled by the added metal. $\mathrm{Mg} / \mathrm{n}$ indicates addition of both $\mathrm{Mg}^{2+}$ and $\mathrm{Mn}^{2+}$; E indicates excess addition of EDTA to the $\mathrm{Mn}^{2+}$ containing reaction before addition of oligonucleotide F12. 


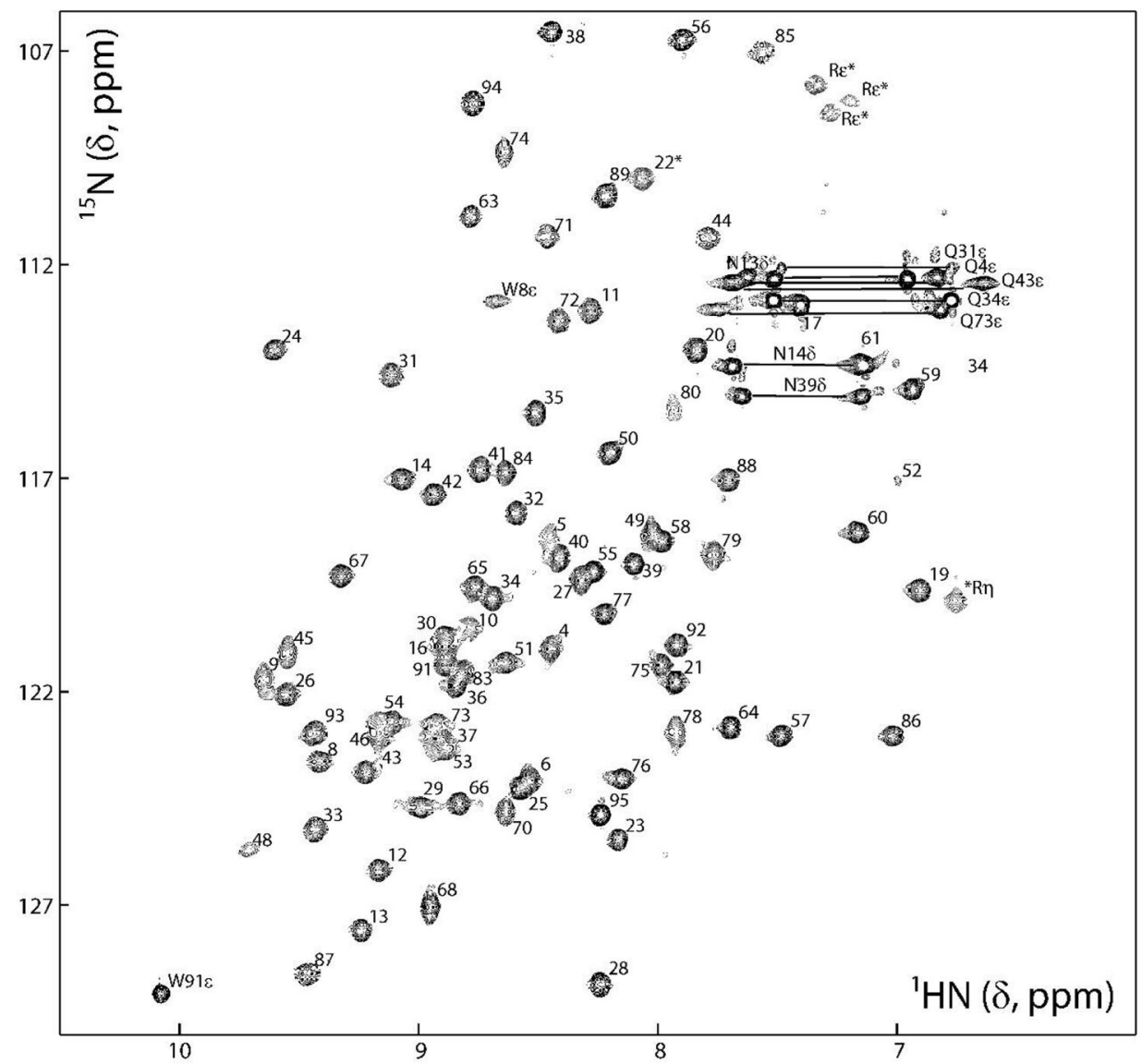

FIGURE 2.

$2 \mathrm{D}{ }^{1} \mathrm{H}-{ }^{15} \mathrm{~N}$ HSQC spectrum of FBNYV M-Rep $2-95$ ( $0.6 \mathrm{mM}$ in $20 \mathrm{mM}$ sodium phosphate, $\mathrm{pH}$ 6.6, $0.6 \mathrm{M} \mathrm{NaCl}, 1 \mathrm{mM}$ DTT, $8 \% \mathrm{D}_{2} \mathrm{O}$ ). Backbone amide resonances are labeled according to residue position in the protein sequence and the side chain $\mathrm{NH}_{2}$ signals are connected and labeled by residue type and number. Likewise, the side chain $\mathrm{NH}$ resonances of Trp and Arg residues are labeled by residue type and number, and position in the side chain. Folded signals in the ${ }^{15} \mathrm{~N}$ dimension are marked with asterisks. 


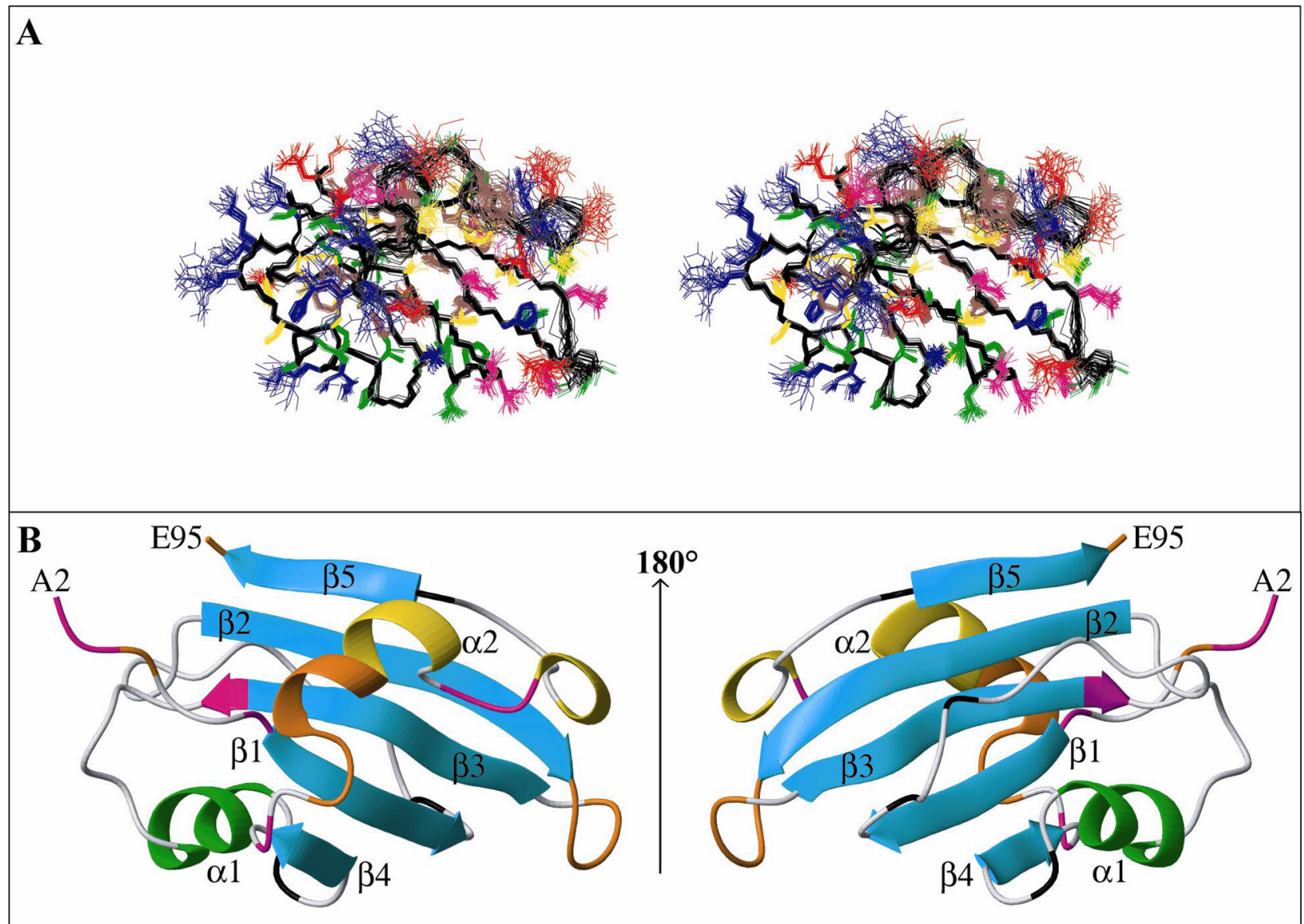

FIGURE 3.

Three-dimensional structure of FBNYV M-Rep2-95. (A) Stereoview representation displaying best-fit superpositions of 30 conformers in the final ensemble (residues 5 to 95). Backbone heavy atoms are shown in black while side chain heavy atoms are displayed in blue (H,K,R), red (D,E), brown (F,Y,W), green (A,I,L,P,V), yellow (C,M,S,T), and magenta (N,Q). (B) Ribbon representations of M-Rep2-95. The central 5-stranded $\beta$-sheet is shown in cyan, the helix $\alpha_{1}$ in green, and the helix $\alpha_{2}$ carrying the catalytic tyrosine is colored in yellow. The strands and helices are numbered and the $\mathrm{N}$ - and $\mathrm{C}$-termini labeled. Loop residues exhibiting substantial flexibility $\left({ }^{15} \mathrm{~N}\left\{{ }^{1} \mathrm{H}\right\} \mathrm{NOE}<0.7\right)$ or non-detected $\mathrm{NH}$ resonances are colored in orange and magenta, respectively. Proline residues are colored in black. 


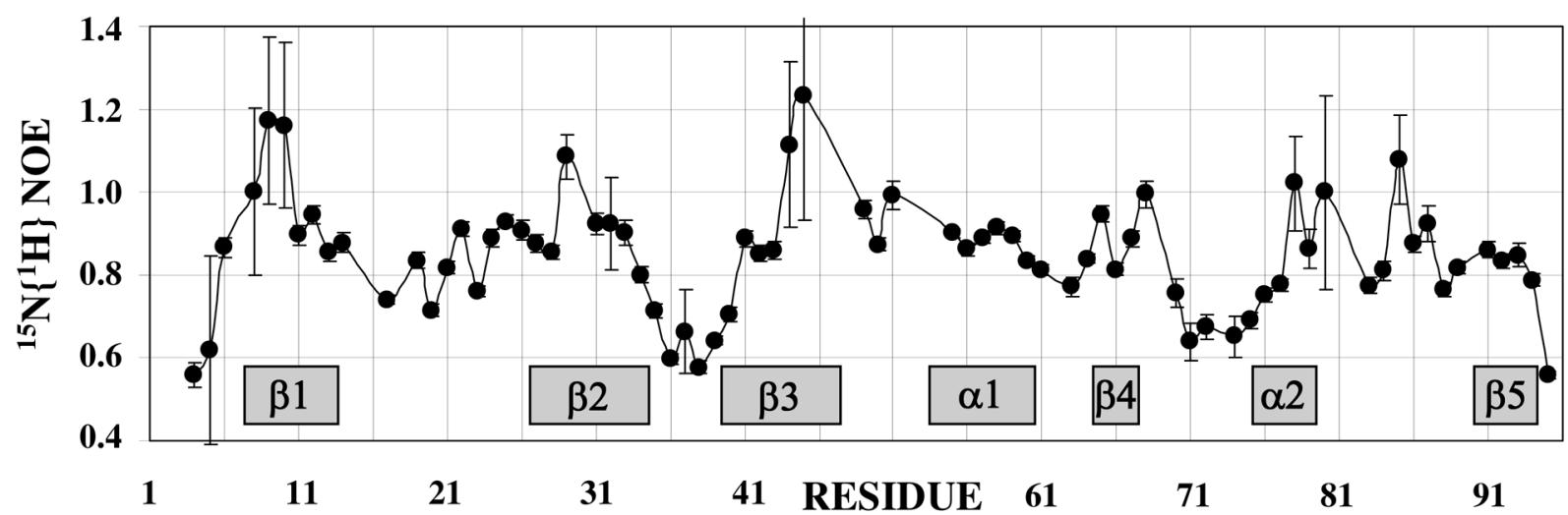

FIGURE 4.

Heteronuclear ${ }^{15} \mathrm{~N}\left\{{ }^{1} \mathrm{H}\right\}$ NOE values of the backbone amides of FBNYV M-Rep2-95. Errors are indicated as vertical lines for each point. Secondary structure elements are indicated by grey boxes. 


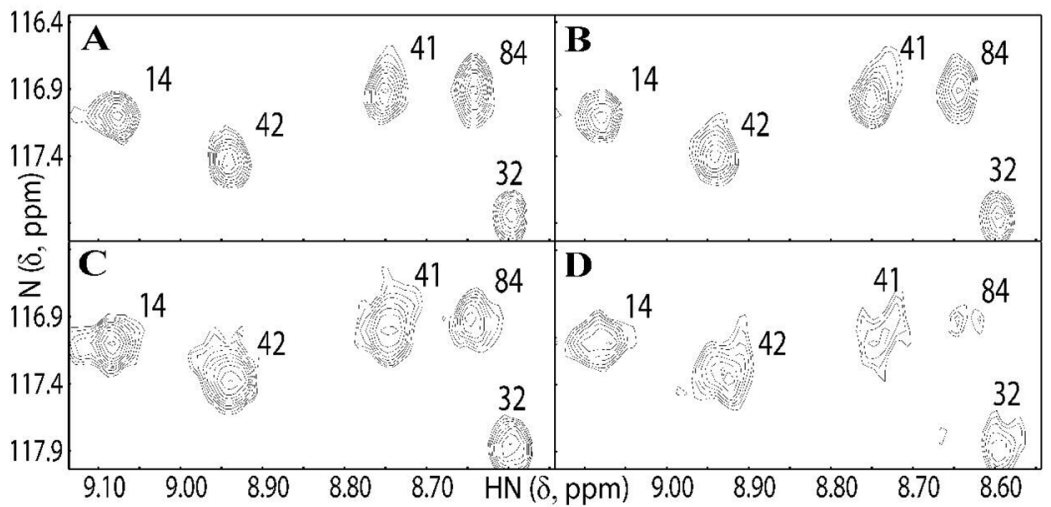

FIGURE 5.

Region of the 2D ${ }^{1} \mathrm{H}_{-}{ }^{15} \mathrm{~N}$ HSQC spectra of FBNYV M-Rep $2-95$ illustrating the decrease in signal intensity in the free protein (A), upon addition of 0.4 (B), 0.8 (C), and 1.6 (D) molar equivalents of $\mathrm{MnCl}_{2}$. Intensities (contour levels) were normalized and resonances are labeled by residue number in the polypeptide sequence. 


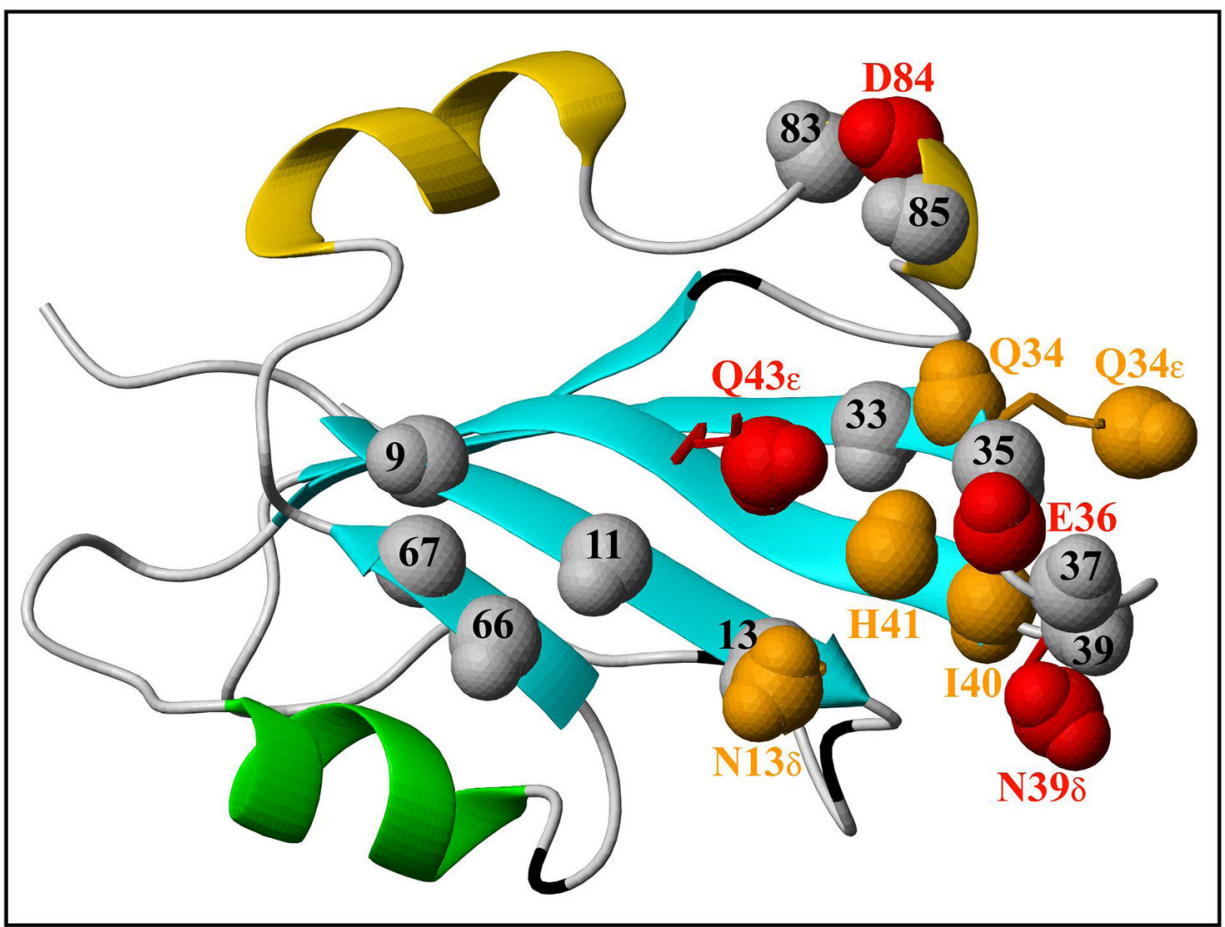

FIGURE 6.

Localization of amide sites affected by manganese binding in the structure of FBNYV MRep $2-95$. The strongly affected sites are represented as red spheres, less affected ones in orange, and borderline ones in grey (see text). Perturbed $\mathrm{NH}_{2}$ side chain sites are shown as sticks in red or orange with the $\mathrm{NH}_{2}$ atoms displayed as spheres. 


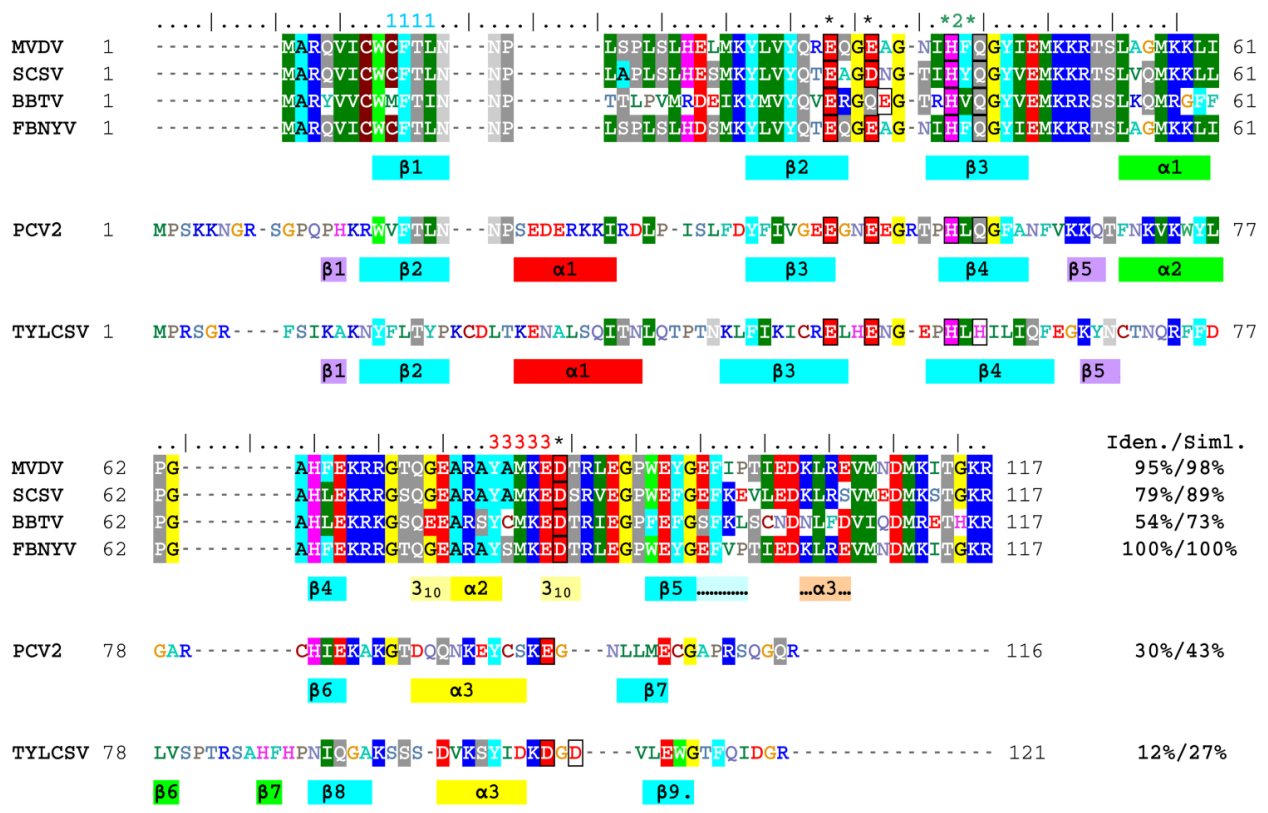

FIGURE 7.

Structure-based alignment of the Rep endonuclease domain sequences from the nanoviruses faba bean necrotic yellows virus (FBNYV, accession number $\underline{\mathbf{0 3 9 8 2 8}}$ ), milk vetch dwarf virus (MVDV, NP_619769), subterranean clover stunt virus (SCSV, NP_620694), and banana bunchy top virus (BBTV, NP_604483)), the circovirus porcine circovirus type 2 (PCV2, $\underline{\mathbf{A A Q 9 4 0 9 8}}$ ), , and the geminivirus tomato yellow leaf curl Sardinia virus (TYLCSV, CAA43466). The secondary structure elements present in FBNYV M-Rep2-95 (identical color coding as in Figure 3B), as well as those in the extension Tag ${ }^{21}-\mathrm{M}-\mathrm{Rep}_{1-.117}$ (indicated with “..." and highlighted in pale blue and orange), together with those of the previously determined structures of the Rep endonuclease domains of PCV2 (20) and TYLCSV (13) are displayed below the corresponding sequences. The conserved RCR initiator protein sequence motifs 1 , 2 , and 3 are labeled above the alignment by $1111, * 2 *$, and 33333 , respectively. Putative divalent metal binding residues are boxed and labeled above the alignment by an asterisk. The pale yellow bars flanking helix $\alpha_{2}$ in FBNYV indicate regions adopting a $3_{10}$ helix conformation (see text). Sequence identities (Iden.) and similarities (Siml.) of the different sequences compared to the FBNYV Rep sequence are provided at the end of the alignment. 

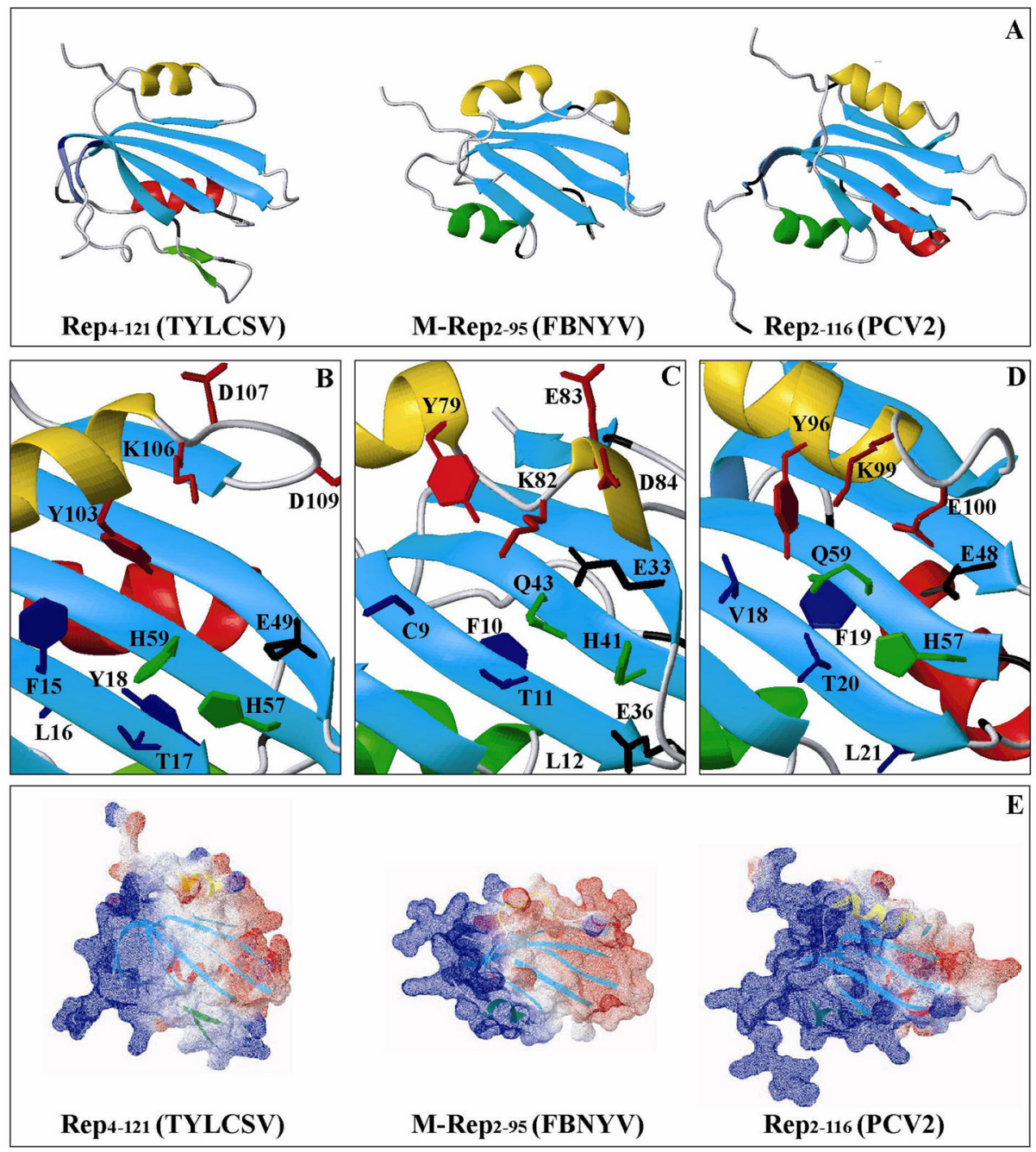

FIGURE 8.

Comparison of the three dimensional structures of the viral RCR initiator endonuclease domains from the geminivirus TYLCSV (PDB 1L2M, left), the nanovirus FBNYV (PDB $2 \mathrm{HWT}$, center) and the circovirus PCV2 (PDB 2HWO, right). Ribbon representation (A): $\beta$ strands in the central $\beta$-sheet are depicted in cyan and $\alpha$-helices in yellow, red and green. Active site regions of TYLCSV (B), FBNYV (C), and PCV2 (D) endonuclease domains, including residues in the conserved sequence motifs I (blue), II (green), and III (red), as well as putative metal binding residues not present in these motifs (black). Electrostatic surface representation (E) of TYLCSV (left), FBNYV (center) and PCV2 (right). Negative and positive potentials are colored red and blue, respectively, with neutral regions in white. Secondary structure elements are visible through the partially transparent surface and color coded as in (A) (generated with Swiss-PdbViewer 3.7 (33)). 
Table 1

Experimental Data and Structural Statistics of the 30 conformers representing the solution structure of M-Rep2-95.

\section{A. NMR-derived constraints}

\begin{tabular}{|c|c|c|c|c|}
\hline $\begin{array}{l}\text { Total interproton } \\
\text { Intraresidue } \\
\text { Sequential }(\mathrm{i}-\mathrm{j}=1) \\
\text { Short range }(1<\mathrm{i}-\mathrm{j}<5) \\
\text { Long range }(\mathrm{i}-\mathrm{j}>4) \\
\text { Total dihedral angles } \\
\varphi \\
\phi_{1} \\
\chi^{1} \\
\text { Total number of } \\
\text { constraints } \\
\text { Total number of } \\
\text { constraints per residue }\end{array}$ & & & & $\begin{array}{c}1248 \\
177 \\
340 \\
168 \\
563 \\
110 \\
52 \\
52 \\
6 \\
1358 \\
14.8\end{array}$ \\
\hline \multicolumn{5}{|l|}{ B. Structural Quality } \\
\hline \multicolumn{5}{|l|}{ 1. Residual violations ${ }^{a}$} \\
\hline & Upper limits & Lower limits & Van der Waals & Torsions \\
\hline $\begin{array}{l}\text { Number of violations } b \\
\text { Maximum violation }\end{array}$ & $\begin{array}{c}19 \pm 6(8 ; 33) \\
0.27 \pm 0.06(0.17 ; 0.39)\end{array}$ & $\begin{array}{c}0 \pm 0(0 ; 0) \\
0.02 \pm 0.01(0.01 ; 0.04)\end{array}$ & $\begin{array}{c}11 \pm 2(7 ; 15) \\
0.21 \pm 0.03(0.17 ; 0.31)\end{array}$ & $\begin{array}{c}0 \pm 0(0 ; 1) \\
3.76 \pm 1.08(2.62 ; 8.12)\end{array}$ \\
\hline
\end{tabular}

CYANA target function

$1.77 \pm 0.23(1.32 ; 2.17)$

$\left(\AA^{2}\right)$

2. Ramachandran statistics ${ }^{c}$

\begin{tabular}{|c|c|c|}
\hline & 30-conformer ensemble & Regularized mean structure \\
\hline $\begin{array}{l}\text { Residues in most favoured } \\
\text { regions }\end{array}$ & $75.5 / 81.7$ & $76.3 / 82.1$ \\
\hline $\begin{array}{l}\text { Residues in additional } \\
\text { allowed regions }\end{array}$ & $19.9 / 16.5$ & $19.7 / 16.1$ \\
\hline $\begin{array}{l}\text { Residues in generously } \\
\text { allowed regions }\end{array}$ & $3.3 / 1.8$ & $2.6 / 1.8$ \\
\hline $\begin{array}{l}\text { Residues in disallowed } \\
\text { regions }\end{array}$ & $1.3 / 0.0$ & $1.3 / 0.0$ \\
\hline \multicolumn{3}{|c|}{ C. Coordinate precision $(\AA, \text { mean/pairwise })^{d}$} \\
\hline & Folded domain ${ }^{e}$ & Well-defined residues $^{e}$ \\
\hline $\mathrm{N}, \mathrm{C}_{\alpha}, \mathrm{C}^{\prime}$ & $0.50 \pm 0.13 / 0.75 \pm 0.17(0.32 ; 0.83) /(0.31 ; 1.24)$ & $0.23 \pm 0.05 / 0.40 \pm 0.08(0.16 ; 0.33) /(0.19 ; 0.67)$ \\
\hline All heavy atoms & $0.95 \pm 0.13 / 1.37 \pm 0.17(0.78 ; 1.28) /(0.88 ; 1.79)$ & $0.70 \pm 0.12 / 1.03 \pm 0.15(0.52 ; 0.97) /(0.66 ; 1.41)$ \\
\hline
\end{tabular}

${ }^{a}$ Average values, standard deviation, and maximum and minimum values (in brackets) for the 30 conformer ensemble. Upper limit, lower limit, and van der Waals violations are given in $\AA$, and torsion violations in degrees.

${ }^{b}$ Number of distance constraint violations larger than $0.1 \AA$ (upper limits, lower limits, van der Waals), and torsional constraint violations larger than 5 degrees.

${ }^{c}$ The 76/56 non-Gly, non-Pro residues in the folded/well-defined region 7-118/7-34,39-68,85-118 of the 30 conformers and those of the regularized mean structure are considered separately. Values are in percent.

${ }^{d}$ Average r.m.s difference between the 30 conformer ensemble and the regularized mean structure/pairwise r.m.s difference between members of the ensemble.

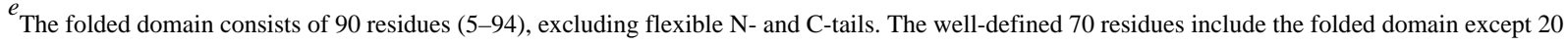
residues (35-38 \& 69-84) located in flexible loops. 